\title{
Rural and Urban Differences in the Adoption of New Health Information and Medical Technologies
}

\author{
David A. Haggstrom, Joy L. Lee, Stephanie L. Dickinson, Sina Kianersi, Jamie L. Roberts, \\ Evgenia Teal, Layla B. Baker, Susan M. Rawl
}

\begin{abstract}
Background: This statewide survey sought to understand the adoption level of new health information and medical technologies, and whether these patterns differed between urban and rural populations.

Methods: A random sample of 7,979 people aged 18-75, stratified by rural status and race, who lived in one of 34 Indiana counties with high cancer mortality rates and were seen at least once in the past year in a statewide health system were surveyed.

Results: Completed surveys were returned by 970 participants. Rural patients were less likely than urban to use electronic health record messaging systems $(28.3 \%$ vs. $34.5 \%, p=0.045)$ or any communication technology $(43.0 \%$ vs. $50.8 \%, p=0.017)$. Rural patients were less likely to look for personal health information for someone else's medical record $(11.0 \%$ vs. $16.3 \%$, $p=0.022)$, look up test results $(29.5 \%$ vs. $38.3 \%, p=0.005)$, or use any form of EMR access (57.5\% vs. $67.1 \%, p=0.003)$. Rural differences in any use of communication technology or EMRs were no longer significant in adjusted models, while education and income were significant. There was a trend in the higher use of low-dose CT scan among rural patients (19.1\% vs. $14.4 \%, p=0.057)$. No significant difference was present between rural and urban patients in the use of the HPV test $(27.1 \%$ vs. $26.6 \%, p=0.880)$.

Conclusions: Differences in health information technology use between rural and urban populations may be moderated by social determinants. Differential adoption of new HIT and medical technologies among rural and urban individuals may be due to varying levels of evidence supporting of these technologies.
\end{abstract}

This is the author's manuscript of the article published in final edited form as:

Haggstrom, D. A., Lee, J. L., Dickinson, S. L., Kianersi, S., Roberts, J. L., Teal, E., Baker, L. B., Rawl, S. M. (2019). Rural and Urban Differences in the Adoption of New Health Information and Medical Technologies. The Journal of Rural Health, 35(2), 144-154. https://doi.org/10.1111/jrh.12358 


\section{INTRODUCTION}

Rural patients previously diagnosed with cancer are more likely to report poor or fair health, psychological distress, and health-related unemployment. ${ }^{1}$ Access to effective primary care is commonly gauged by the rate of ambulatory care-sensitive hospitalizations, which are higher among adults in living in rural areas. ${ }^{2}$ To improve access, patient-centered technologies are increasingly incorporated as a component of health care delivery for patients to both communicate with their health care providers and access their electronic medical record (EMR). Patient-to-provider communication technologies are available both external and internal to the EMR platform of health care providers. Although the professional and ethical uses of such technologies are a matter of debate ${ }^{3}$, patients can communicate with their providers through existing technologies, including e-mail, text messages, social media, and video conferencing applications like Facetime or Skype. In terms of EMR use, patients can review their own medical records, or in the role of caregiver, the personal health information of others. Furthermore, EMR platforms commonly enable patients to review their tests results or refill medications.

Relatively little is known about how rural populations meet their health care needs through the use of health information technology. A study among US Veteran patients and providers found that a lack of adequate technology infrastructure was seen as an obstacle to health care utilization. ${ }^{4}$ Limited broadband access is considered an important barrier to the use of information technology in rural areas ${ }^{5}$, and may explain known disparities in personal information technology use, as well as hospital adoption of health information technology.

New medical technologies also have become widely available in the past decade for the purpose of cancer screening. In 2013, low-dose CT (LDCT) scans for lung cancer screening were recommended by the US Preventive Services Task Force (USPSTF) among previous or current smokers ages $55-80 .{ }^{6}$ Among women, human papilloma virus (HPV) testing was recommended in 2012 as an option for cervical cancer screening from age 30-65 by the 
USPSTF. ${ }^{7}$ Prior research has not focused upon the adoption of these new cancer screening approaches among rural populations. In addition to worse health status, rural populations oftentimes receive care from hospitals with lower quality of care. ${ }^{8}$

Health information technologies and medical technologies are similar enough that it is informative to consider them together. Access to both of these technologies is of significant importance to the quality of life and health of rural communities. ${ }^{9}$ Population health increasingly considers the multi-sectoral influences upon the health of individuals living in a community, including not only the health care delivery system, but also infrastructure and other social sectors that either directly or indirectly influence the health of individuals.

In the United States, current policy debates regarding the needs of rural communities have weighed the relative merits of access to health care through expanded Medicaid insurance versus access to broadband Internet. ${ }^{10}$ Just as these policy debates are best conducted by weighing the benefits of these different types of community capacity together, considering the pace and predictors of change in medical and health information technologies together provides a fuller characterization of the state of rural health.

The diffusion of new innovations or technologies framework, as conceptualized by Rogers et al., ${ }^{11}$ has been adapted to the health care setting by Berwick et al. ${ }^{12}$ How the diffusion of innovation differs between health information and medical technologies has not been widely explored. How these dissemination patterns may differ between urban and rural groups is also unknown. For this study, we performed a population, state-based survey of Indiana residents to understand the level of adoption of new health information and medical technologies, and whether these patterns differed between urban and rural populations.

\section{METHODS}

Survey population: Young, middle-aged, and older adults were surveyed in order to obtain a multi-generational perspective upon cancer information-seeking behavior. Surveying 
young adults also enabled us to better assess HPV testing among women. We set the upper age limit of our sample at 75 years because, after that age, most types of cancer screening are not recommended. Rural and African American populations were oversampled in order to have adequate power to test for differences in technology adoption among these vulnerable groups (racial differences reported elsewhere). Stratification was evenly based on geographic location and race; urban/rural status was prioritized over race. Individuals residing in one of 34 counties with relatively high cancer mortality rates within the state (194.7 to 234.6 deaths per 100,000 people $)^{13}$ were surveyed because the overall effort was intended to guide efforts to address unmet needs in the population catchment area of the Indiana University Cancer Center (IUCC). The age-adjusted mortality rate of Indiana is 185.2 per 100,000 , which is significantly higher than the national rate $(168.5$ per 100,000$) .^{14}$

Survey sample: Adult patients age 21-75 who were identified as White/Caucasian or Black/African-American in their electronic medical record were included.

A list of individuals who had been seen at least once in the past 12 months at an Indiana University Health (IUH) facility was generated that included names, addresses, race, and age. IUH is a statewide-integrated healthcare system with 19 hospitals in Indiana, and with the inclusion of outpatient practices or testing services, encompasses 178 clinics. From the list of 284,062 persons who met inclusion criteria, a random, stratified sample of 8,000 individuals was generated to survey. The intention was to sample 2,000 participants from each of four strata (rural White, rural African-American, urban White, urban African-American), but there were only 524 individuals in the rural African-American category, so all 524 were sampled, with the remainder of the 2,000 taken from the rural White category, to ensure 4,000 total rural and 4,000 urban. The proportion of African-Americans in the US population overall is $12.2 \%$ and the state of Indiana is $9.7 \%$. In terms of regional comparisons, the proportion of the overall AfricanAmerican population that lives in different regions of the country is as follows: South (55\%), 
Midwest (17\%), Northeast (18\%), and West (10\%). ${ }^{15}$ Hispanic, Asian, Native American and other ethnic groups were excluded from the original sampling frame because, while their needs are very important, the sample sizes would have been inadequate to make meaningful statistical comparisons among these smaller groups. According to the American Community Survey (2017), the proportion of patients from these different ethnic categories in Indiana are as follows: Hispanic or Latino (7.0\%), Asian (2.4\%), or Native American (0.4\%). We reasonably anticipate that the rural proportions are even lower.

Rural location was defined by Rural Urban Community Area (RUCA) codes from the census tract (rural defined as large rural city/town, small rural town, or isolated small rural town). RUCA codes are based on the same theoretical concepts used by the Office of Management and Budget (OMB) to define county-level metropolitan areas. Similar criteria are applied to measures of population density, urbanization, and daily commuting to identify urban cores and adjacent territory that is economically integrated with those cores. Rural RUCA codes were 4.0, $4.2,5.0,5.2,6.0,6.1,7.0,7.2,7.3,7.4,8.0,8.2,8.3,8.4,9.0,9.1,9.2,10.0,10.2,10.3,10.4$, 10.5, 10.6, and urban RUCA codes were 1, 1.1, 2, 2.1, 3, 4.1, 5.1, 7.1, 8.1, 10.1. ${ }^{16}$

Data Collection: A list was generated from the Indiana University Health (IUH) electronic data warehouse regarding the primary care provider (PCP) associated with each patient. These PCPs received a single email providing them with an opt-out procedure to exclude their patients. PCPs were given 2 weeks to indicate he/she did not want the individual invited to participate in the survey. Among the 34 PCPs contacted, 2 PCPs selected patients they allowed to be approached, 2 refused all patients; and 30 agreed to all patients being contacted. Based upon responses from the PCPs, 21 patients were not invited to participate in the survey; therefore, the final number of mailed surveys was 7,979 . This list and process was managed by a practice-based research network (PBRN) associated with the Indiana University School of Medicine that functions independent of the study team. 
In January and February 2018, the Indiana University Center for Survey Research (CSR) mailed packages to the survey sample. Following the tailored design method ${ }^{17}$, the first mailing included the survey instrument, cover letter introducing the study, study information sheet, HIPAA authorization form, a postage-paid, pre-addressed envelope to return the completed survey, and an advance incentive of a $\$ 1$ bill. Two weeks later, a postcard reminder was sent; one month later, a second copy of the survey and reminder letter was mailed to nonrespondents. The Indiana University-Purdue University Institutional Review Board approved the study.

Respondents returned paper surveys and authorization forms which were then reviewed and tagged with serial numbers and dispositions in a tracking database. Quality control tests were done to verify scanning precision and data accuracy. Staff examined completed surveys for illegible marks, corrected them when necessary to enhance data capture, and digitally scanned them.

Response rates were lower for African-American compared to White ( $8 \%$ vs. $14 \%$, $p<0.001)$ respondents, and young $(18-49$ years) compared to older $(50-75$ years) individuals ( $6 \%$ vs. $15 \%, p<0.001)$. Response rates were higher in rural areas compared to urban areas ( $13 \%$ vs. $11 \%$ respectively, $p=0.009)$.

Measures: To facilitate harmonization of data collected, data sharing and the ability to merge datasets across cancer centers, project leaders worked closely with National Cancer Institute $(\mathrm{NCl})$ staff to determine specific items to be included in the final survey. Project leaders, $\mathrm{NCl}$ staff, and investigators from 15 other cancer centers evaluated and agreed upon a core set of survey items to assess: individual and sociodemographic characteristics, and health promoting/cancer prevention behaviors including screening; and access to health care. Relevant items were identified from the Health Information National Trends Survey (HINTS), the Behavioral Risk Factor Surveillance System (BRFSS) survey, and the National Health and Nutrition Examination Survey (NHANES). 


\section{Independent predictors:}

Sociodemographic Characteristics: Individual sociodemographic data collected included age (categorical), sex (male vs. female), education (categorical), employment, home ownership, and income (categorical), and race. For sampling purposes, race data were obtained from the electronic medical record (EMR), but race was then confirmed or replaced by our gold standard of self-report. For race, agreement between EMR and survey self-report was 0.951 (Phi coefficient).

Broadband: Individuals were asked "In the past 12 months, when you have used the Internet, did you access it through Broadband such as DSL, cable or FiOS?" (Yes or no). Fios refers to fiber optic service.

\section{Dependent outcomes:}

New health information technology use: For communication technology, patients were asked "In the past 12 months, have you used the following ways to communicate with your doctor or a doctor's office?" Yes/no responses were provided for the following 5 items: "Email", "Electronic health record messaging systems like Epic MyChart", "Text message", "Facebook or other social media sites", and "Skype, Facetime, or other video conference systems". These individual items were combined into an aggregate outcome of "Any communication technology", wherein "Yes" represented use of any single technology, and "No" meant no use of any technology at all.

For electronic medical record (EMR) use, patients were asked "In the past 12 months, have you used a computer, smartphone, or other electronic means to do any of the following?" Yes/no responses were coded for the following 4 items: "Looked for personal health information from your medical record", "Looked for personal health information for someone else's medical record", "Looked up test results", and "Requested a medication refill from your doctor". These individual items were combined into an aggregate outcome of "Any EMR use", wherein "Yes" represented use of any single technology, and "No" meant no use of any technology at all. 
New medical technology use: Completion of a low dose CT scan to screen for lung cancer was measured with the following yes/no question: "Have you ever had a lung scan, also called a low-dose CT scan, to screen for lung cancer?" Only individuals ages 55-75 who had 30 pack-years or greater of smoking history were included in the denominator for this measure. HPV testing was assessed with another yes/no question: "An HPV test is sometimes given with the Pap test for cervical cancer screening. Have you ever had an HPV test?" Women ages 2165 who had never had a hysterectomy were included in the measure's denominator. In the case of both measures, having ever used these medical technologies--as opposed to guidelineconcordant cancer screening-was assessed to better capture the construct of technology adoption and diffusion.

Data analysis. Descriptive statistics were performed on individual sociodemographic characteristics, broadband availability, and technology use. Survey weights were created to account for the stratified sample and oversampling of rural and African-American individuals and used to calculate weighted estimates and standard errors for the population. Overall descriptive statistics were performed as well as separately by rural and urban status. To examine differences in sociodemographics, broadband, and technology use, proportions for each response were first compared between rural vs. urban groups using Pearson chi-square tests. Since education and income were the only multinomial categorical variables with overall significant $p$-values, we performed bivariate logistic regression analysis to compare each level with a reference level

Multivariable logistic regression models were then performed for each outcome with predictor variables for geographic location (rural/urban), age group, sex, race, education, employment, home ownership, and income. For the health information technology outcomes (communication and EMR use), broadband was also included in the models. In all, four models were performed predicting the aggregate outcomes of new health information technology use (any communication or EMR use), as well as the individual outcomes of new medical 
technology use (LDCT scan or HPV testing ever). The SurveyLogistic procedure in the SAS System for Windows version 9.4 was used to account for survey weights and the stratified sampling design which projects data from the sample to estimate rates in the larger population. Adjusted Odds Ratios and 95\% confidence intervals are reported from the logistic models.

\section{RESULTS}

Survey population: Of the 7,979 surveys mailed, 970 were returned completed yielding a $12 \%$ response rate. Overall, 54 refused directly, 28 refused implicitly (blank survey returned), 27 were deceased or physically/mentally unable to participate, two were determined out of sample, and 586 were returned undeliverable. As shown in Table 1, compared to urban respondents, rural respondents had a lower proportion in the African-American group (8.5\% vs. $34.9 \%, p<0.001)$. Lower proportions of rural residents were employed $(36.4 \%$ vs. $46.7 \%$, $p=0.006)$, but higher proportions owned their own home $(75.4 \%$ vs. $60.2 \%, p<0.001)$. Between urban and rural participants, there were also significant differences in education and income. While rural areas more often have a high school diploma as their highest degree ( $32 \%$ of rural vs $24 \%$ of urban), urban residents more often have a college degree ( $42 \%$ of urban vs $32 \%$ of rural). For income, rural residents less often have a household income $\geq \$ 100,000$ (12\% of rural vs. $22 \%$ of urban).

Differences in New Health Information Technology Use: Rural participants were less likely than their urban counterparts to use electronic health record messaging systems (28.3\% vs. $34.5 \%, p=0.045)$ or any communication technology $(43.0 \%$ vs. $50.8 \%, p=0.017)$ in bivariate comparisons (Table 2). Rural participants were less likely than urban participants to look for personal health information for someone else's medical record $(11.0 \%$ vs. $16.3 \%, p=0.022)$, look up test results $(29.5 \%$ vs. $38.3 \%, p=0.005)$, or any form of EMR use $(57.5 \%$ vs. $67.1 \%$, $\mathrm{p}=0.003)$. 
Rural differences in the use of any communication technology (AOR $=0.91,95 \%$ $\mathrm{Cl}=0.55-1.48$; reference, urban $)$ or any $\mathrm{EMR}$ use $(\mathrm{AOR}=0.81,95 \% \mathrm{Cl}=0.47-1.39$; reference, urban) were not significant in adjusted models (Table 3). Independent predictors that were significantly associated with any communication use included some college or vocational training (AOR=3.69, 95\% $\mathrm{Cl}=1.09-12.47$; reference, less than high school) and income $\geq \$ 100,000(\mathrm{AOR}=4.40,95 \% \mathrm{Cl}=1.27-15.27$; reference, $\$ 0-19,999)$. The likelihood of any EMR use was higher among retired and unemployed individuals ( $\mathrm{AOR}=3.64,95 \% \mathrm{Cl}=1.48-8.96$; reference, employed), , the unemployed ( $\mathrm{AOR}=2.78,95 \% \mathrm{Cl} 1.18-6.52)$; reference, employed), and African-Americans (2.45, 95\% Cl 1.08-5.58; reference, White); but EMR use was lower among those without broadband access $(\mathrm{AOR}=0.36,95 \% \mathrm{Cl}=0.18-0.73$; reference, broadband access).

Differences in New Medical Technology Use: Bivariate comparisons (Table 2) showed a trend in the higher use of low-dose CT (LDCT) scan ever among rural (compared to urban) patients ( $19.1 \%$ vs. $14.4 \%, p=0.057)$. No significant difference was present between rural and urban patients in ever having an HPV test $(27.1 \%$ vs. $26.6 \%, p=0.880)$. In adjusted models (Table 4), rural populations still had no significantly different likelihood of ever having an LDCT scan for lung cancer screening ( $A O R=5.20,95 \% \mathrm{Cl}=1.00-27.11$; reference, urban) or an $\mathrm{HPV}$ test for cervical cancer screening ( $\mathrm{AOR}=0.84,95 \% \mathrm{Cl}=0.31-2.25$; reference, urban).

In adjusted models, other individual characteristics associated with ever having an LDCT scan included high school graduation $(\mathrm{AOR}=0.02,95 \% \mathrm{Cl}=<0.01-0.42$; reference, less than high school) or some college or vocational training (AOR $=0.01,95 \% \mathrm{Cl}=<0.01-0.36$; reference, less than high school), as well as unemployment $(\mathrm{AOR}=0.03,95 \% \mathrm{Cl}=<0.01-0.51$; reference, employed). For HPV testing, some college or vocational training was associated with a greater likelihood of this cancer screening test $(A O R=22.46,95 \% \mathrm{Cl}=1.01-501.05$; reference, less than high school). 


\section{DISCUSSION}

Adoption of health information technologies was lower among rural than urban respondents seeking care in a statewide academic health care delivery system. These differences were moderated, at least in part, by social determinants, including income (communication, EMR use) and education (communication). Rural Americans have lower median household incomes than urban households, although people living in rural areas have lower poverty rates than their urban counterparts. ${ }^{15}$ Also, U.S. rural populations on average have lower levels of educational achievement. ${ }^{18}$ These national patterns are consistent with the characteristics of our state-based sample and provide some insight into lower use of health IT among rural residents. More anomalous findings from our survey included greater EMR use among African-American and unemployed populations. Racial disparities have previously been identified in patient use of personal or electronic health records in a managed care organization. ${ }^{19}$ EMR use among the unemployed has not been well-described, but while nonworking individuals may have worse health status, ${ }^{20}$ they may also have greater time opportunity to access EMRs via patient portals. These unexpected patterns of health information technology use deserve research and confirmation in other studies. In any setting, obstacles to adoption of health information technologies include patients' technology preferences, the technology's design and usability, as well as the need to reimburse providers for their care.

Broadband availability emerged as a significant factor in EMR use among our population. Today, roughly two-thirds of American adults have broadband internet service at home, but such access is less common among rural residents. ${ }^{21}$ Rural broadband has more commonly been discussed in terms of the benefit to economic development ${ }^{22}$, but successful policies to expand broadband access also have the potential to improve health through patients' access to, and use of, their EMR. 
The adoption of new medical technologies appeared to be the same across rural and urban settings, including a trend towards greater adoption of LDCT scans for lung cancer screening among rural patients. Based upon data modeling, others have speculated that radiology capacity constraints may limit the adoption of LDCT scans in rural areas; however, our findings do not support these concerns. ${ }^{23}$ One potential explanation for equivalent rural/urban adoption of lung cancer screening may be the financial incentives in the health care system. LDCT can be a "loss leader" for medical/surgical facilities, leading to multiple diagnostic and therapeutic downstream services, an especially valuable impact at financially challenged rural hospitals. ${ }^{24}$

\section{$\underline{\text { Communication technologies }}$}

Although the majority rural residents (58\% as of 2015$)$, like their urban and suburban counterparts (64\% and $68 \%$, respectively), use social media, their rates of adoption have consistently lagged behind urban/suburban residents. ${ }^{25}$ The overall use of health communication technologies among our state-based sample appeared higher than previously studied populations. Population-level estimates of patients' use of technologies to communicate with their providers are rare. Instead, studies most often report the percentage of users who have signed up to use secure messaging within an EMR system. For example, of the 5.9 million Veteran's Health Administration (VA) patients receiving health care services in 2017, approximately $42 \%$ had access to secure messaging. ${ }^{26}$ In 2013 , the Health Information National Trends Survey (HINTS), a nationally representative US survey, found that $30 \%$ of Internetaccessing U.S. adults reported communicating with a healthcare provider using the Internet or email. ${ }^{27}$ Our findings regarding e-mail use (24\%), in particular, appear lower than these prior surveys. However, when we consider any communication technology (e-mail, secure messaging systems or texts), our estimates are somewhat higher (47\%).

The adoption of communication technologies that enable patient-provider communication is associated with high patient satisfaction. ${ }^{28}$ Although the evidence base on the 
clinical effects of communication technologies is still developing ${ }^{29}$ several studies have found the use of secure messaging to be associated with good diabetes control. ${ }^{30-32}$

\section{EMR use}

Beyond allowing patients to communicate with their providers, the EMR provides a number of other functions of interest and use to patients in managing their own care, including accessing personal health information, test results, and requesting medication refills. Existing studies have rarely tested the impact of these EMR-based functions upon clinical outcomes, but a number of studies have reported improvements in quality of care indicators, such as disease awareness, medication adherence, and self-management were associated with patient use of EMRs. $^{33}$

A 2016 report found that although rural providers first adopted electronic health record systems at rates similar to urban counterparts, there were disparities between urban and rural providers regarding meaningful use attestation in the latter stages. ${ }^{34}$ The overall access of the EMR among our state-based sample appeared higher than previously studied populations. In the 2013 HINTS survey, $28 \%$ of U.S. adults reported tracking their personal health information (PHI) electronically, such as care received, test results, or upcoming medical appointments. Meanwhile, in $2018,35 \%$ of Indiana residents surveyed reported looking for personal health information from their medical record, and 62\% reported having any EMR use (access own PHI, access other person's $\mathrm{PHI}$, test results, or medication refill). These different rates may be due to either temporal or regional trends. US levels of adoption should continue to be compared and contrasted with state-based patterns in future research, but likely, public policy should be considered at both levels.

\section{Cancer screening}

The overall rate of LDCT scans for lung cancer screening among our state-based sample (17\%) appeared higher than previously studied populations. A study using 2010 and 2015 National Health Interview Survey (NHIS) data--a nationally representative, in-person 
household survey--estimated the proportion of high-risk current and former smokers (who quit in the past 15 years) who had undergone LDCT for lung cancer screening in the past year did not change and remained below $4 \% .{ }^{35}$ Currently accepted approaches to lung cancer screening are associated with reductions in both lung cancer (20\%) and all-cause mortality $(6.7 \%) .{ }^{36}$ It is challenging to assess national rates of HPV testing because population-based cervical cancer screening involves an overall strategy combining the HPV test with cytology. Similarly, although it is difficult to disentangle the individual test effects of a combined HPV and cytology strategy upon clinical outcomes, a randomized trial clearly established a mortality benefit in reduced cervical cancer deaths with one-time HPV screening in never-screened women aged 30 to 59 years compared to no screening. ${ }^{37}$

One potential reason for the differential adoption of new health information and medical technologies among rural and urban populations is that rural settings may be more likely to adopt new technologies when more supporting evidence is available. As the discussion here highlights, new medical technologies related to cancer screening currently have a more robust evidence-base supporting their implementation than new health information technologies.

According to the "diffusion of innovation" theory of Rogers et al, when a new technology has a more clearly understood benefit, then change is more likely to be adopted. Other technology characteristics that are considered important factors in the adoption of innovation include complexity, trialability, and observability. ${ }^{12}$ All of these factors conceivably favor more rapid adoption of new medical technology than health information technology. New cancer screening technologies require relatively simple adjustments to existing clinical services in the case of LDCT scans (radiology) and HPV tests (pathology). Similarly, these new screening services are both trialable (can initially be performed on a small-scale) and observable (potential adopters can watch others attempt the change first). In contrast, the adoption of new health information technologies usually involves complex organizational changes for implementation. ${ }^{38}$ Installments of new health information technologies oftentimes need to be done on a system- 
wide basis, limiting opportunities for trial or observation beforehand. As to why rural health care communities may be slower to adopt such innovation, answers to this question may relate to both differences in the number of innovators in rural versus urban communities, as well as the degree to which health care leadership and encourages such changes. The observations here are consistent with the adoption curve of electronic medical records, wherein small, rural hospitals have been slower to adopt EMRs than their urban counterparts. ${ }^{39}$ While the application of theory provides several possibilities for differential rates of adoption of new technologies in varied locations, these explanations deserve further exploration and testing via mixed methods, including multiple stakeholder interviews that could further elucidate why patients and providers together, in a shared geographical context, may favor one course for navigating change over another.

$\underline{\text { Limitations }}$

Several limitations of this study should be noted. First, our sample was recruited from a large, state-wide, academic health care system. Thus, overall rates of both health information and medical technology use may be higher than among a population who has not accessed the health care system in the past year. However, among individuals who have some interaction with the same health care system, and for reasons of equity, there is no reason that rates of technology adoption should differ between urban and rural populations. Also, the response rate of $12 \%$ is low, for instance, compared to the response rate of rural community dwelling older adults in Utah (31\%). ${ }^{40}$ Yet our survey sample also included younger and working adults who may be less likely to respond to mailings. ${ }^{41}$ In anticipation of a low response rate, we mailed enough surveys to obtain a relatively large absolute number of surveys among rural and African-American individuals, two groups among whom we were concerned about the presence of disparities in access to new technologies.

\section{$\underline{\text { Conclusions }}$}


Rural participants were less likely than their urban counterparts to use electronic health record messaging systems, look for personal health information as a caregiver, or look up test results in an electronic medical record. These differences were moderated by the social determinants of education and income. Conversely, there were no significant differences in the use of new medical technologies, namely LDCT for lung, or HPV tests for cervical cancer among rural patients. Strong clinical evidence defines the benefit of new cancer screening technologies, while the evidence base supporting the use of patient-centered health information technologies is less robust. These varying levels of evidence may help to explain the differential adoption of new HIT and medical technologies in rural versus urban settings. Diffusion of innovation theory provides other potential explanations for geographic differences in technology utilization worth exploration in the future. 


\section{REFERENCES}

1. Weaver KE, Geiger AM, Lu L, Case LD. Rural-urban disparities in health status among US cancer survivors. Cancer. Mar 1 2013;119(5):1050-1057.

2. Laditka JN, Laditka SB, Probst JC. Health care access in rural areas: evidence that hospitalization for ambulatory care-sensitive conditions in the United States may increase with the level of rurality. Health \& place. Sep 2009;15(3):731-740.

3. DeCamp M, Koenig TW, Chisolm MS. Social media and physicians' online identity crisis. JAMA. 2013;310(6):581-582.

4. Schooley BL, Horan TA, Lee PW, West PA. Rural veteran access to healthcare services: investigating the role of information and communication technologies in overcoming spatial barriers. Perspectives in health information management. 2010;7:1f.

5. Tomer A, Kneebone E, Shivaram R. (2017, Septemer 12). Signs of digital distress: mapping broadband availability and subscription in American neighborhoods. The Brookings Institution, Metropolitan Policy Program. Accessed on November 23, 2018 https://www.brookings.edu/research/signs-of-digital-distress-mapping-broadbandavailabilityl.

6. Humphrey LL, Deffebach M, Pappas M, et al. Screening for lung cancer with low-dose computed tomography: a systematic review to update the US Preventive services task force recommendation. Ann Intern Med. 2013;159(6):411-420.

7. Moyer VA. Screening for cervical cancer: U.S. Preventive Services Task Force recommendation statement. Ann Intern Med. 2012;156(12):880-891, w312.

8. Nawal Lutfiyya M, Bhat DK, Gandhi SR, Nguyen C, Weidenbacher-Hoper VL, Lipsky MS. A comparison of quality of care indicators in urban acute care hospitals and rural critical access hospitals in the United States. Int J Qual Health Care. 2007;19(3):141149.

9. Douthit N, Kiv S, Dwolatzky T, Biswas S. Exposing some important barriers to health care access in the rural USA. Public Health. 2015 Jun;129(6):611-20.

10. Goodnough, A. ( 2018, October 20). Stacey Abrams Hopes Medicaid Expansion Can Be a Winning Issue in Rural Georgia. New York Times. Accessed on November 23, 2018 at https://www.nytimes.com/2018/10/20/health/medicaid-georgia-abrams-midterms.html.

11. Rogers EM. Diffusion of Innovations. 4th ed. New York, NY: Free Press; 1995.

12. Berwick DM. Disseminating innovations in health care. JAMA. 2003;289(15):1969-1975.

13. Indiana Cancer Consortium, Indiana Cancer Facts and Figures, Table 4, Indiana Cancer Mortality (Death) Rates by County, 2008-2012. Accessed on August 12, 2018 at http://indianacancer.org/wp-content/uploads/2015/05/Indiana-Cancer-Facts-and-Figures2015_web.pdf.

14. American Cancer Society. Cancer Facts \& Figures 2017. Atlanta. American Cancer Society, 2017. Accessed on March 15, 2017 at https://www.cancer.org/content/dam/cancerorg/research/cancer-facts-andstatistics/annual-cancer-facts-and-figures/2017/cancer-facts-and-figures-2017.pdf

15. US Census Bureau, 2011-2015, American Community Survey. Accessed on November 25, 2018 at https://www.census.gov/newsroom/blogs/randomsamplings/2016/12/a_comparison_of_rura.html.

16. Rural Health Researchl Center. RU $\bar{U} \overline{C A}$ Data. http://depts.washington.edu/uwruca/rucauses.php Accessed August 12, 2018.

17. Dillman DA, Smyth JD, Christan LM. Internet, phone, mail, and mixed-mode surveys: The tailored design method. 4th ed. Hoboken, New Jersey: Wiley; 2014.

18. Provasnik S, KewalRamani, A., Coleman, M.M., Gilbertson, L., Herring, W., and Xie, Q. Status of Education in Rural America (NCES 2007-040), National Center for Education 
Statistics, Institute of Education Sciences, U.S. Department of Education. Washington, D.C.2007.

19. Roblin DW, Houston TK, 2nd, Allison JJ, Joski PJ, Becker ER. Disparities in use of a personal health record in a managed care organization. JAMIA. 2009;16(5):683-689.

20. Janlert $U$, Winefield $A H$, Hammarstrom $A$. Length of unemployment and health-related outcomes: a life-course analysis. Eur J Public Health. 2015;25(4):662-667.

21. Pew Research Center. Internet/Broadband Fact Sheet. Accessed on August 12, 2018 at http://www. pewinternet.org/fact-sheet/internet-broadband/.

22. Prieger JE. The broadband digital divide and the economic benefits of mobile broadband for rural areas. Telecommunications Policy. 2013;37(6-7):483-502.

23. Smieliauskas F, MacMahon H, Salgia R, Shih YC. Geographic variation in radiologist capacity and widespread implementation of lung cancer CT screening. J Med Screen. 2014;21(4):207-215.

24. Kaufman BG, Thomas SR, Randolph RK, et al. The Rising Rate of Rural Hospital Closures. J Rural Health. 2016;32(1):35-43.

25. Perrin A. (2015, October 8). Social Media Usage: 2005-2015. Pew Research Center. Accessed on November 25, 2018 at http://www.pewinternet.org/2015/10/08/socialnetworking-usage-2005-2015/\#social-media-usage-by-community-type-more-than-halfof-rural-residents-now-use-social-media.

26. Hogan TP, Luger TM, Volkman JE, Rocheleau M, Mueller N, Barker AM, Nazi KM, Houston TK, Bokhour BG. Patient Centeredness in Electronic Communication:

Evaluation of Patient-to-Health Care Team Secure Messaging. J Med Internet Res. 2018 Mar 8;20(3):e82.

27. Jackson DN, Chou WS, Coa KI, Oh A, Hesse B. Implications of social media use on health information technology engagement: Data from HINTS 4 cycle 3. Translational behavioral medicine. Dec 2016;6(4):566-576.

28. Haun JN, Patel NR. Large-Scale Survey Findings Inform Patients' Experiences in Using Secure Messaging to Engage in Patient-Provider Communication and Self-Care Management: A Quantitative Assessment. Dec 21 2015;17(12):e282.

29. Atherton H, Sawmynaden P, Sheikh A, Majeed A, Car J. Email for clinical communication between patients/caregivers and healthcare professionals. The Cochrane database of systematic reviews. 2012;11:Cd007978.

30. Chung S, Panattoni L, Chi J, Palaniappan L. Can Secure Patient-Provider Messaging Improve Diabetes Care? Diabetes Care. 2017;40(10):1342-1348.

31. Shimada SL, Allison JJ. Sustained Use of Patient Portal Features and Improvements in Diabetes Physiological Measures. 2016;18(7):e179.

32. Zhou YY, Kanter MH, Wang JJ, Garrido T. Improved Quality At Kaiser Permanente Through E-Mail Between Physicians And Patients. Health Affairs. 2010;29(7):13701375.

33. Kruse CS, Bolton $\mathrm{K}$. The effect of patient portals on quality outcomes and its implications to meaningful use: a systematic review. 2015;17(2):e44.

34. Helsey-Grove DM. Variation In Rural Health Information Technology Adoption And Use. Health Affairs 2016;35(2):365-70.

35. Jemal A, Fedewa SA. Lung Cancer Screening With Low-Dose Computed Tomography in the United States-2010 to 2015. JAMA oncology. 2017;3(9):1278-1281.

36. Aberle DR, Adams AM, Berg CD, et al. Reduced lung-cancer mortality with low-dose computed tomographic screening. N Engl J Med. 2011;365(5):395-409.

37. Sankaranarayanan R, Nene BM, Shastri SS, et al. HPV screening for cervical cancer in rural India. N Engl J Med. 2009;360(14):1385-1394. 
38. Westbrook JI, Braithwaite J, Georgiou A, et al. Multimethod evaluation of information and communication technologies in health in the context of wicked problems and sociotechnical theory. JAMIA. 2007;14(6):746-755.

39. Adler-Milstein J, Holmgren AJ, Kralovec P, Worzala C, Searcy T, Patel V. Electronic health record adoption in US hospitals: the emergence of a digital "advanced use" divide. JAMIA. 2017;24(6):1142-1148.

40. Edelman LS, Yang R, Guymon M, Olson LM. Survey methods and response rates among rural community dwelling older adults. Nursing research. 2013;62(4):286-291.

41. Fowler Jr FJ. Survey research methods. Sage publications; 2013. 
Table 1. Survey sample sociodemographics

\begin{tabular}{|c|c|c|c|c|}
\hline Patient characteristics & $\begin{array}{l}\text { Total } \\
\text { n (\%) }\end{array}$ & $\begin{array}{l}\text { Rural } \\
\text { n (\%) }\end{array}$ & $\begin{array}{l}\text { Urban } \\
\mathrm{n}(\%)\end{array}$ & $\begin{array}{c}\text { p - } \\
\text { value* }\end{array}$ \\
\hline Age Group: & & & & 0.103 \\
\hline $18-34$ & $105(10.82)$ & $50(9.56)$ & $55(12.30)$ & \\
\hline $35-49$ & $130(13.40)$ & $73(13.96)$ & $57(12.75)$ & \\
\hline $50-64$ & $380(39.18)$ & $193(36.90)$ & $187(41.83)$ & \\
\hline $65+$ & $355(36.60)$ & $207(39.58)$ & $148(33.11)$ & \\
\hline Sex: & & & & 0.656 \\
\hline Female & $522(53.81)$ & $278(53.15)$ & $244(54.59)$ & \\
\hline Male & $448(46.19)$ & $245(46.85)$ & $203(45.41)$ & \\
\hline Race: & & & & $<.001^{*}$ \\
\hline $\begin{array}{l}\text { African- } \\
\text { American }\end{array}$ & $192(20.53)$ & $43(8.46)$ & $149(34.89)$ & \\
\hline White & $743(79.47)$ & $465(91.54)$ & $278(65.11)$ & \\
\hline Education: & & & & $0.008^{*}$ \\
\hline$<$ High school & $71(7.75)$ & $38(7.66)$ & $33(7.86)$ & $0.341^{1}$ \\
\hline HS graduate & $260(28.38)$ & $159(32.06)$ & $101(24.05)$ & $0.034^{1}$ \\
\hline $\begin{array}{l}\text { Some college or } \\
\text { vocational }\end{array}$ & $253(27.62)$ & $142(28.63)$ & $111(26.43)$ & $0.001^{1}$ \\
\hline $\begin{array}{l}\text { College graduate } \\
\text { or postdoctoral } \\
\text { (Reference) }\end{array}$ & $332(36.24)$ & 157 (31.65) & $175(41.67)$ & \\
\hline Employed: & & & & $0.006^{*}$ \\
\hline Yes & $369(41.14)$ & $177(36.42)$ & $192(46.72)$ & \\
\hline No & $225(25.08)$ & $128(26.34)$ & $97(23.60)$ & \\
\hline Retired & $303(33.78)$ & $181(37.24)$ & $122(29.68)$ & \\
\hline Own Home: & & & & $<.001$ \\
\hline Yes & $638(68.38)$ & $379(75.35)$ & $259(60.23)$ & \\
\hline No & $295(31.62)$ & $124(24.65)$ & $171(39.77)$ & \\
\hline Income & & & & $<.001^{*}$ \\
\hline$\$ 0-19,999$ & $177(20.46)$ & $83(18.00)$ & $94(23.27)$ & 0.131 \\
\hline$\$ 20 K-49,999$ & $268(30.98)$ & $164(35.57)$ & $104(25.74)$ & $<.001^{1}$ \\
\hline$\$ 50 K-99,999$ & 277 (32.02) & 159 (34.49) & $118(29.21)$ & $<.001^{1}$ \\
\hline $\begin{array}{ll} & \$ 100 \mathrm{~K}+ \\
& \text { (Reference) }\end{array}$ & $143(16.53)$ & 55 (11.93) & $88(21.78)$ & \\
\hline \multicolumn{5}{|l|}{ Broadband } \\
\hline Yes & $321(41.96)$ & $177(42.24)$ & $144(41.62)$ & 0.862 \\
\hline No & $444(58.04)$ & $242(57.76)$ & $202(58.38)$ & \\
\hline
\end{tabular}

${ }^{*} \mathrm{p}$-values $<0.05$ for each variable overall are from Pearson Chi-square tests.

${ }^{1}$ Because education and income were significant across 4 levels, bivariate logistic regression was performed to test each level individually with the reference level (< High School, and $\$ 100 \mathrm{~K}+)$. 
Table 2. Adoption of new technologies, by rural status

\begin{tabular}{|c|c|c|c|c|}
\hline New technology use & $\begin{array}{l}\text { Total } \\
\text { n }(\%)\end{array}$ & $\begin{array}{l}\text { Rural } \\
\text { n (\%) }\end{array}$ & $\begin{array}{l}\text { Urban } \\
\text { n (\%) }\end{array}$ & p - value* \\
\hline \multicolumn{5}{|l|}{ New health information technology use } \\
\hline \multicolumn{5}{|l|}{ Communication technology } \\
\hline Email & $218(24.14)$ & $107(21.70)$ & $111(27.07)$ & 0.061 \\
\hline Electronic health record messaging systems & $283(31.10)$ & $140(28.28)$ & $143(34.46)$ & $0.045^{*}$ \\
\hline Text message & $158(17.81)$ & $80(16.53)$ & $78(19.35)$ & 0.273 \\
\hline Facebook or other social media sites & $16(1.83)$ & $10(2.10)$ & $6(1.52)$ & 0.524 \\
\hline $\begin{array}{l}\text { Skype, Facetime, or other video conference } \\
\text { systems }\end{array}$ & $22(2.51)$ & $8(1.67)$ & $14(3.53)$ & 0.081 \\
\hline Any communication technology & $434(46.57)$ & $218(43.00)$ & $216(50.82)$ & $0.017^{*}$ \\
\hline \multicolumn{5}{|l|}{ Electronic medical record (EMR) access } \\
\hline $\begin{array}{l}\text { Looked for your personal health information from } \\
\text { your medical record }\end{array}$ & $319(35.29)$ & $161(32.59)$ & $158(38.54)$ & 0.063 \\
\hline $\begin{array}{l}\text { Looked for personal health information for someone } \\
\text { else's medical record }\end{array}$ & $117(13.40)$ & $52(10.97)$ & $65(16.29)$ & $0.022^{*}$ \\
\hline Looked up test results & $299(33.52)$ & $142(29.46)$ & $157(38.29)$ & $0.005^{*}$ \\
\hline Requested a medication refill from your doctor & $416(46.64)$ & $217(44.93)$ & 199 (48.66) & 0.266 \\
\hline Any EMR use & $576(61.94)$ & $290(57.54)$ & $286(67.14)$ & $0.003^{*}$ \\
\hline \multicolumn{5}{|l|}{ New medical technology use } \\
\hline Low-dose CT scan ever: & & & & 0.057 \\
\hline Yes & $159(16.95)$ & $97(19.09)$ & $62(14.42)$ & \\
\hline No & $779(83.05)$ & $411(80.91)$ & $368(85.58)$ & \\
\hline \multicolumn{5}{|l|}{ HPV test ever: } \\
\hline Yes & $144(26.87)$ & $76(27.14)$ & $68(26.56)$ & 0.880 \\
\hline No & $392(73.13)$ & $204(72.86)$ & $188(73.44)$ & \\
\hline
\end{tabular}

${ }^{*}$ p-values $<0.05$ from Pearson Chi-square tests. 
Table 3: Likelihood of new health information technology use for communication or electronic medical record use

\begin{tabular}{|c|c|c|c|}
\hline & & $\begin{array}{c}\text { Communication } \\
\text { AOR }(95 \% \mathrm{CI}) \\
\mathrm{n}=594^{\mathrm{b}}\end{array}$ & $\begin{array}{c}\text { EMR use } \\
\text { AOR }(95 \% \mathrm{Cl}) \\
n=596^{b}\end{array}$ \\
\hline \multirow[t]{2}{*}{ Rural status: } & Urban & 1.00 (ref.) & 1.00 (ref.) \\
\hline & Rural & $0.91(0.55-1.48)$ & $0.81(0.47-1.39)$ \\
\hline \multirow[t]{4}{*}{ Age Group: } & $18-34$ & 1.00 (ref.) & 1.00 (ref.) \\
\hline & $35-49$ & $1.09(0.37-3.16)$ & $0.38(0.12-1.14)$ \\
\hline & $50-64$ & $0.92(0.35-2.39)$ & $0.54(0.21-1.39)$ \\
\hline & $65+$ & $0.44(0.15-1.29)$ & $0.46(0.14-1.45)$ \\
\hline \multirow[t]{2}{*}{ Sex: } & Male & 1.00 (ref.) & 1.00 (ref.) \\
\hline & Female & $0.96(0.52-1.76)$ & $1.09(0.57-2.08)$ \\
\hline \multirow[t]{2}{*}{ Race: } & White & 1.00 (ref.) & 1.00 (ref.) \\
\hline & African-American & $0.80(0.37-1.73)$ & \\
\hline \multirow[t]{4}{*}{ Education: } & $<$ High school & 1.00 (ref.) & 1.00 (ref.) \\
\hline & $\begin{array}{l}\text { High school } \\
\text { graduate }\end{array}$ & $1.31(0.38-4.52)$ & $0.43(0.14-1.34)$ \\
\hline & $\begin{array}{l}\text { Some college or } \\
\text { vocational training }\end{array}$ & $3.69(1.09-12.47)^{*}$ & $1.32(0.40-4.35)$ \\
\hline & College graduate & $3.43(0.97-12.10)$ & $1.10(0.33-3.69)$ \\
\hline \multirow[t]{3}{*}{ Employed: } & Yes & 1.00 (ref.) & 1.00 (ref.) \\
\hline & No & $0.98(0.43-2.26)$ & $2.78(1.18-6.52)^{*}$ \\
\hline & Retired & $1.84(0.81-4.15)$ & $3.64(1.48-8.96)^{*}$ \\
\hline \multirow[t]{2}{*}{ Own Home: } & Yes & 1.00 (ref.) & 1.00 (ref.) \\
\hline & No & $1.36(0.60-3.08)$ & $0.81(0.36-1.80)$ \\
\hline \multirow[t]{4}{*}{ Income: } & $\$ 0-19,999$ & 1.00 (ref.) & 1.00 (ref.) \\
\hline & $\$ 20 K-49,999$ & $0.90(0.33-2.43)$ & $2.05(0.75-5.55)$ \\
\hline & $\$ 50 K-99,999$ & $1.21(0.42-3.43)$ & $1.65(0.57-4.78)$ \\
\hline & $\$ 100 K+$ & $4.40(1.27-15.27)^{*}$ & $3.63(1.06-12.42)^{*}$ \\
\hline \multirow[t]{2}{*}{ Broadband: } & Yes & 1.00 (ref.) & 1.00 (ref.) \\
\hline & No & $0.76(0.37-1.58)$ & $0.36(0.18-0.73)^{*}$ \\
\hline
\end{tabular}

${ }^{*} p<0.05$

AOR = Adjusted Odds Ratio

a. Maximum number of observations used in crude analysis.

b. Number of observations used in the multivariate model, due to missing data in covariates 
Table 4: Likelihood of ever having lung cancer screening and HPV testing

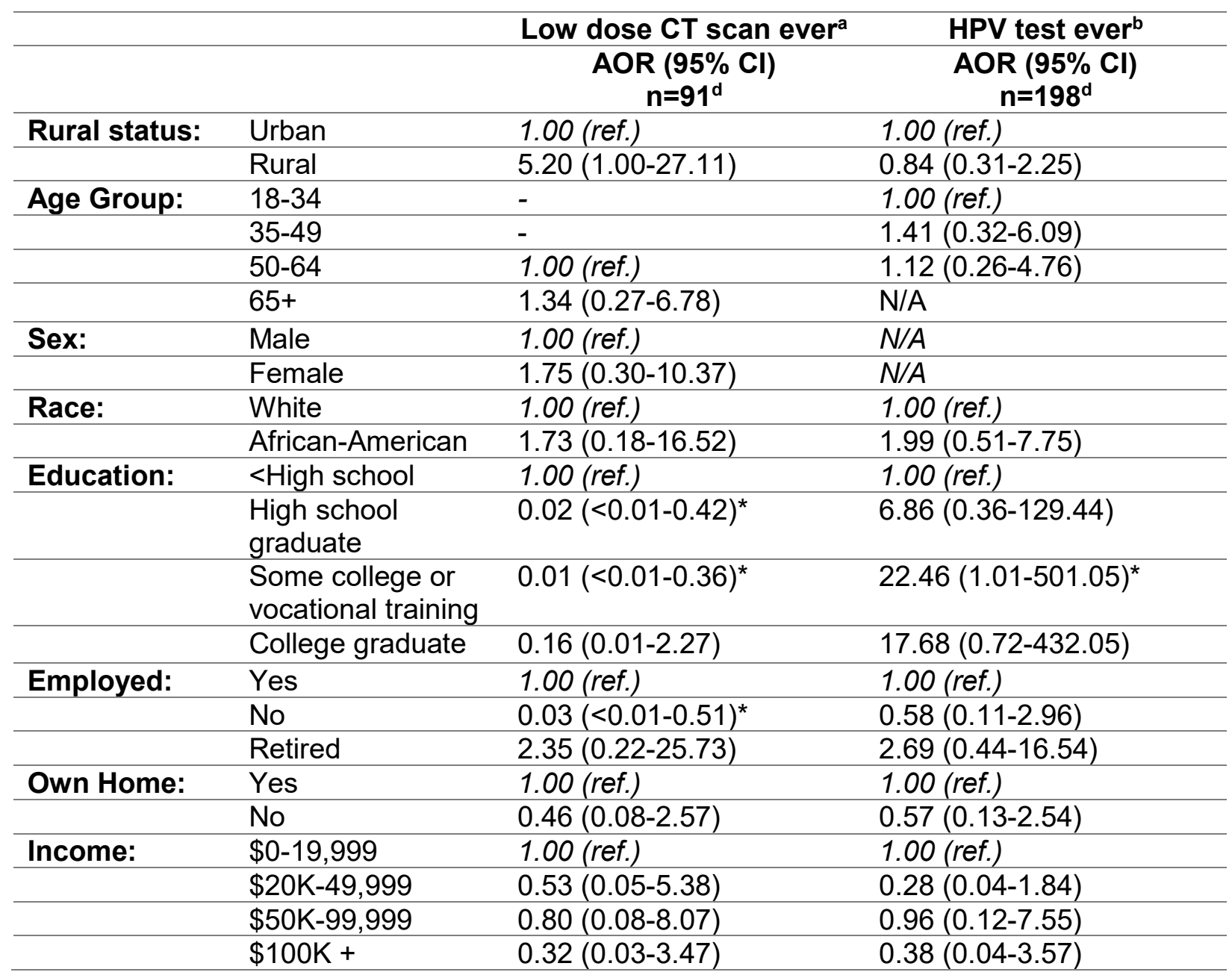

${ }^{*} \mathrm{p}<0.05$

a. For "Lung cancer screening" only participants who were 55 to 80 years old and smoked more than 30 pack-years were included in the analysis $(n=113)$.

b. For "HPV testing" only women who were 21 to 65 years old and haven't had a hysterectomy were included in the analysis $(n=238)$.

c. Maximum number of observations used in crude analysis.

d. Number of observations used in the multivariate model, due to missing data on covariates. 